\title{
Does Social Capital Matter for Supply Chain Resilience? The Role of Absorptive Capacity and Marketing-Supply Chain Management Alignment
}

by

\author{
Ismail Gölgeci $^{\text {1\# }}$ and Olli Kuivalainen ${ }^{2}$
}

${ }^{\mathbf{1} D r .,}$ Associate Professor of Marketing Strategy, School of Business and Social Sciences,
Department of Business Development and Technology, Aarhus University, Birk Centerpark 15,
Building 8001, 7400 Herning, Denmark. Email: i.golgeci@btech.au.dk

${ }^{2}$ Professor of International Marketing and Entrepreneurship, LUT School of Business and Management, Lappeenranta University of Technology, P.O.B. 20, 53851 Lappeenranta, Finland, E-mail: olli.kuivalainen@lut.fi

and

Professor of International Business and Management, Alliance Manchester Business School, The University of Manchester, Booth Street West, Manchester M15 6PB, United Kingdom, E-mail: olli.kuivalainen@manchester.ac.uk

\section{\#Corresponding author}

\begin{abstract}
Marketing in an increasingly tumultuous marketplace requires resilience -the ability to withstand, adapt, and flourish despite turmoil and adverse change- that extends beyond firm boundaries. Although external resources are arguably essential to achieve resilience, little is known how and when firms' social capital derived from interorganizational relationships can lead to supply chain resilience. Therefore, we investigate the role of absorptive capacity and marketing-supply chain management alignment in realizing the potential impact of social capital on supply chain resilience. Using data obtained from dual respondents from 265 Turkish firms, we test the mediating role of absorptive capacity and the moderating role of marketing-supply chain management alignment. Our findings indicate absorptive capacity mediates the relationship between social capital and supply chain resilience, and the links between social capital and absorptive capacity and social capital and supply chain resilience are stronger when marketingsupply chain management alignment is high. We also find that supply chain resilience is positively associated with organizational performance, empirically supporting the proposed value of supply chain resilience for firm strategy. Accordingly, our paper highlights that both absorptive capacity and marketing-supply chain management alignment are necessary to realize the actual value of social capital for supply chain resilience and ensuing performance.
\end{abstract}

\section{Keywords}

Supply chain resilience; social capital; absorptive capacity; marketing-supply chain management alignment 


\section{Introduction}

In today’s highly connected global marketplace, risks and disruptions are becoming unquantifiable threats to long-term success and survival (Colicchia \& Strozzi, 2012) and overturning firm-centric traditional management practices that assume steady conditions (Pettit, Croxton, \& Fiksel, 2013). Each day, firms face disruptions that can jeopardize their ability to perform effectively. For example, Boeing's plan to introduce 787 Dreamliner and outrun its major competitors was plagued by severe and unexpected supply chain disruptions causing significant production delays and cost hikes as well as putting Boeing’s supply chain resilience into question (Melnyk et al., 2014). Further, for example, when trade sanctions were imposed between Russia and 25 other countries in 2014, import-dependent Russian firms had to reorganize their supply chain very rapidly against such major disruption. Laine and Galkina (2017, pp. 916-919) describe the case of Russian SMEs in the shipbuilding industry, which sourced $90 \%$ of their inputs from imports, and how they reconfigured their supply chain from the mostly Western providers toward Chinese. A firm manager describes their approach: "Through the years, we were using our portfolio of established relationships, where everything was stable and predictable...” With a proactive development of R\&D and production processes and business relationships -alongside operating with the existing supply chain partners- the firm was able to develop a relationship with one Chinese firm. When the disruption occurred overnight, they were able to increase the volumes of orders with this supplier at a reasonably low level of risk, as they had already developed a certain degree of trust and social capital. Eventually, they not only serve their existing customers but also to increase their market share by taking over the market from competitors who struggled with their supplies (ibid).

It is, therefore, becoming critical for firms to build supply chain resilience (SCR) as a pivotal capability to respond to challenges, adversities, and uncertainties (Sheffi \& Rice, 2005), and embrace complexity to create sustained customer value in settings where firms and their advantages are often short-lived. Nonetheless, the sheer magnitude of adversities and disruptions firms face may make relying solely on internal resources unviable for long-term survival and performance. In this paper, we focus on social capital 
-external resources derived from networks of social relationships (Tsai, 2001)- as a potential enabler of SCR through the mediating means of absorptive capacity and under the contingency of the alignment between marketing and supply chain management (SCM). In this way, we connect absorptive capacity and marketing-SCM alignment as critical factors that link social capital to SCR.

Social capital is widely recognized as a fundamental resource for firms (Inkpen \& Tsang, 2005; Nahapiet \& Ghoshal, 1998; Partanen et al., 2008; Tsai \& Ghoshal, 1998). However, research on the link between social capital and resilience has produced inconsistent results based on weak evidence (Aldrich, 2012; Aldrich \& Meyer, 2015; Johnson, Elliott, \& Drake, 2013). For example, whereas Johnson et al. (2013) position social capital as an enabler of the emergence of formative capabilities for SCR, Aldrich and Meyer (2015) highlight the role of social capital and networks in disaster survival and recovery. Thus, the depth of the link between social capital and resilience is yet to be fully explored (Aldrich, 2012). In particular, little is known about how social capital can be utilized in the face of adversity and turbulence, and under what conditions its influence on SCR is more pronounced. Furthermore, although an extensive research on SCR view it as a critical capability for thriving in dynamic environments (Gölgeci \& Ponomarov, 2015; Lengnick-Hall \& Beck, 2009; Mccann, Selsky, \& Lee, 2009; Ponomarov \& Holcomb, 2009), there is little empirical evidence as to whether SCR lead to increased organizational performance.

Absorptive capacity (Tsai, 2001; Zahra \& George, 2002) is a salient boundary-spanning capability to utilize intangible resources derived from firm's interorganizational relationships, as external resources do not act on themselves and can have both positive and negative consequences (Pillai et al., 2017). Absorptive capacity capitalizes on key resources embedded in the firm's relationships and enables effective deployment of such resources for continued competitive advantage. Nonetheless, the role of firms' cross-functional alignment strategies cannot be disregarded when examining absorptive capacity, as it is embedded in contexts in which it is applied (Trentin, Forza, \& Perin, 2015). Alignment of the firm's value-creating functions may have a defining role in the application and effectiveness of absorptive capacity (Jüttner, Christopher, \& Godsell, 2010; Powell, 1992) in SCM and marketing domains to enable resistance to 
adversities and survival against external turbulence. Accordingly, a deeper understanding of the linkages between social capital and absorptive capacity, and the way marketing-SCM alignment moderates these linkages to withstand turmoil and hardships is needed. Likewise, the link between SCR and organizational performance is needed to be empirically established to make grounded arguments on the value of SCR.

The purpose of this study is to investigate the role of absorptive capacity and marketing-SCM alignment in realizing the potential impact of social capital on SCR. We seek to examine how absorptive capacity conveys the role of social capital in the pursuit of SCR under varied levels of marketing-SCM alignment. Using dual responses from 265 participant firms, we test our model that posits absorptive capacity as a mediator to the link between social capital and SCR and marketing-SCM alignment as a moderator to the nexus of these linkages. The findings indicate partial support to our model and confirm the role of absorptive capacity and marketing-SCM alignment in relaying the impact of social capital on SCR.

Our research contributes to marketing and SCM research regarding the role of the firms' absorptive capacity and marketing-SCM alignment in utilizing social capital to achieve SCR. First, to understand the means via which social capital enhances SCR, we suggest that it is necessary to take intermediate capability of absorptive capacity into account. Second, we highlight that marketing-SCM alignment can condition the extent to which social capital can support absorptive capacity. Third, we delve into the outcomes of SCR and reveal that SCR is likely to underpin overall organizational performance. Consequently, we explain the means through and conditions under which firms make the best use of their external resources accumulated as social capital and develop their SCR for improved organizational performance.

\section{Theoretical background}

\subsection{Social capital}

One of the central functions of interorganizational relationships is accumulating and providing social access to resources, i.e., social capital, through specific structures, relationships, and cognition (Borgatti \& Halgin, 2011). Social capital is defined as 'the sum of the actual and potential resources embedded within, available through, and derived from the relationships possessed by an individual or social unit' (Nahapiet \& Ghoshal, 
1998, p. 243). Social capital is composed of structural (overall pattern of connections between actors), cognitive (shared meaning and understanding among network parties), and relational (the kind of personal relationships people have within the network) dimensions (Inkpen \& Tsang, 2005; Nahapiet \& Ghoshal, 1998). Social capital has been recognized to add value to firms in networks (e.g., Borgatti \& Halgin, 2011), as it provides access to resources and information (Inkpen \& Tsang, 2005; Yli-Renko, Autio, \& Sapienza, 2001). It is, thus, well-acknowledged in marketing and SCM literature as a critical element of interorganizational relationships (Partanen et al., 2008; Stolze, Murfield, \& Esper, 2015).

Recent research views social capital as a possible hedge against adversities (Aldrich, 2012; Aldrich \& Meyer, 2015; Johnson et al., 2013). The core premise of this emergent research stream is that social capital can be a crucial relational resource to face, adapt to, and survive adverse change, especially for resource-dependent livelihoods (Adger, 2003). Both strong and weak ties as ingredients of social capital are necessary for resilience, as strong ties provide unique capabilities and social cohesion (i.e., a strong sense of belonging and deep connectedness infusing the network) and weak ties provide access to novel ideas and a diverse set of resources (Jackson \& Young, 2016). Social capital is an external resource that does not necessarily incur proportional costs with increased use (Borgatti \& Halgin, 2011), as its maintenance is not directly dependent on its scale. Thus, firms' need of having slack resources to stay resilient (Linnenluecke, 2017) while watching their cost closely (Pettit et al., 2013) places social capital into a tactful spot to develop and maintain SCR.

However, social capital is also laden with liabilities and can have negative consequences (Pillai et al., 2017). Dysfunctional identification processes can restrict the processing of information, and overcommitment to established relationships leads to postponement of structural adjustments that derail the positive use of social capital and harm resistance to disruptions (Pillai et al., 2017). Likewise, social capital is typically coupled with firms' dependence and reliance on outside entities that can amplify their vulnerability to threats (Pettit et al., 2013). Firms engaging in intensive relationships and building strong social capital can face opportunity costs and high risk of unstable supply (Mitręga \& Zolkiewski, 
2012). Thus, capabilities and processes to alleviate potential negative consequences of social capital and transform social capital into a positive force are necessary.

In the context of SCR, it should be noted that firms may have separate social networks for regular business operations (Acquaah, 2007; Yli-Renko et al., 2001) and emergency operations (Aldrich, 2012; Aldrich \& Meyer, 2015). For instance, there may be numerous government and non-profit organizations that become part of firms' supply chain in emergencies that typically would not be present for regular business operations. Firms must decide regarding which relationships will be most beneficial to recovery in the face of adversity and disruption. Having interorganizational ties with firms operating within supply chains is important but so is having intersectional ties (ties across sectors) (Capaldo, 2007).

\subsection{Marketing-SCM interface}

Marketing and SCM are two fundamental functions primarily responsible for value creation and spanning organizational boundaries (Gölgeci, Karakas, \& Tatoglu, 2019; Hung, 2010; Jüttner et al., 2010; Piercy, 2009). Marketing-SCM interface is the epicenter of boundary-spanning activities, as both functions are primary domains through which firms manage their interorganizational relationships and coordinate their upstream and downstream value creation activities throughout their supply chains (Mentzer, Stank, \& Esper, 2008). Marketing and SCM also serve primary domains and tools for accruing and leveraging social capital (Batt, 2008; Geng et al., 2017; Xiong \& Bharadwaj, 2011). Managers working in marketing and SCM functions establish and manage interorganizational ties and turn them into social capital (Batt, 2008; Jackson \& Young, 2016; Stolze et al., 2015). Therefore, marketing-SCM interface and the interplay between the two functions is essential to understand the role of social capital in achieving SCR.

That said, marketing-SCM interface is a sophisticated context with potential tensions that pose implications for the way a firm conducts its boundary-spanning activities, obtain and process external knowledge, and leverage social capital. Marketing and SCM functions have distinct roles and rely on divergent foundational premises (Piercy, 2009). For instance, Delbridge (2007) found that one outcome of cross-functional activities is 'conflicted collaboration', where collaborative efforts are coupled with 
conflicting values and priorities. Though marketing and SCM functions are often compelled to work together, they often think differently, have different values, and follow different objectives that indicate the challenge of achieving and maintaining the alignment between the two functions (Jüttner et al., 2010).

Moreover, boundary spanners working in marketing and SCM functions can experience subtleties of cross-functional power dynamics and their ensuing challenges that may complicate their knowledge acquisition and assimilation activities (Astley \& Sachdeva, 1984; Corvellec \& Hultman, 2014). As firms’ internal relational dynamics can be expected to be reflected in their interorganizational behavior (Chen, Liu, \& Portnoy, 2012), marketing-SCM interface and whether marketing and SCM functions are aligned or not may condition the way social capital and knowledge-related boundary-spanning capabilities translate into an improved capability to withstand adverse change. Thus, cross-functional relationships manifested at the marketing-SCM interface (Tsai, 2002) can have a salient influence on how firms run boundary-spanning activities, leverage social capital, and achieve SCR.

\subsection{Absorptive capacity as a boundary-spanning capability}

Boundary-spanning activities link firms with their external environment (Williams, 2002). Supply chains are built and sustained by individuals and activities that span interorganizational boundaries (Piercy, 2009). Boundary-spanning activities are underlain by capabilities that facilitate fruitful exchanges and collaborations across organizational boundaries (Zhang, Viswanathan, \& Henke, 2011). Boundaryspanning capabilities enable facilitating dialogue between multiple parties and, thereby, coping with knowledge heterogeneity by translating and relaying information. Hence, boundary-spanning capabilities are leveraged to create firm-level assets by enabling effective communications that enable greater and more effective interactions in supply chains that generate familiarity and trust between collaborating firms.

Firms increasingly depend upon their supply chain (SC) partners’ knowledge to deliver superior value to customers amid environmental turbulence and dynamism (Saenz, Revilla, \& Knoppen, 2014). This transference requires absorptive capacity that refers to routines and processes by which firms acquire, assimilate, transform, and exploit information embedded in the outside of the firm's organizational 
boundaries to produce a dynamic organizational capability (Zahra \& George, 2002). Absorptive capacity is a central overarching concept to explain knowledge management and innovation in marketing and management literature (Najafi-Tavani et al., 2018; Tsai, 2001; Xiong \& Bharadwaj, 2011; Zahra \& George, 2002), and it encompasses marketing capabilities and market-linking capabilities with boundary-spanning attributes (Yaqun et al., 2015).

Absorptive capacity involves a collection of boundary-spanning routines to create and manage external knowledge and continuous learning processes in firms (Liu et al., 2013). Thus, it is a boundary-spanning capability germane to accessing, processing, and utilizing information embedded in the firm's relationships as relevant knowledge in the face of contingencies and hardships. Given its fundamental tenets, absorptive capacity to access and process new external knowledge is particularly vital for firms in turbulent environments that have to cope with ever-changing circumstances (Yaqun et al., 2015).

Acquisition and management of external information are central to absorptive capacity. Connectionist view of network theory investigates contagion as a primary consequence of interorganizational relationships (Borgatti \& Halgin, 2011). This line of thought suggests that the flow of ideas, insights, and information through network channels accumulate into critical knowledge-related resources at firms’ disposal. Nonetheless, firms still need specific capabilities and processes to acquire and harvest these resources. This is when absorptive capacity comes into the picture as a knowledge-centered boundary-spanning capability that could be deployed in networks (Tsai, 2001; Zahra \& George, 2002).

Besides its application on wide variety of phenomena, absorptive capacity has also been investigated in relation to SC risk and uncertainties (Ambulkar, Blackhurst, \& Cantor, 2016; Van Doorn, Heyden, \& Volberda, 2017). This line of literature suggests that acquiring, processing, and exploiting external information is particularly relevant when firms deal with a barrage of adverse changes and their survival is at stake. Absorptive capacity plays a pivotal role in reducing uncertainty (i.e., narrowing the gap between knowledge available and knowledge needed to handle SC risks effectively) (Ambulkar et al., 2016). Firms with higher absorptive capacity are, therefore, argued to be in a better position to face external threats, rise 
to external challenges through entrepreneurial processes, and contain the effect of disruptions (Van Doorn et al., 2017). In this vein, absorptive capacity can enable firms to comprehend and respond quickly to adverse environmental changes and thus facilitate positive change (Yaqun et al., 2015).

\subsection{Supply chain resilience}

Supply chains and firms operating in these networks have witnessed unprecedented levels of turbulence such as natural disasters, political upheavals, and cyber-attacks and market dynamism such as high demand variability and shortening product lifecycles in recent years (Gölgeci \& Ponomarov, 2015; Tukamuhabwa et al., 2015). Enterprises that could not withstand such a storm of change failed, and some ceased to exist (Hollnagel \& Fujita, 2013). Due to such severe consequences, researchers and practitioners emphasized SC designs that are resilient to disruptions and adverse change (Kamalahmadi \& Parast, 2016). Therefore, SCR concept has risen to a notable prominence in recent years.

SCR is defined as "the adaptive capability of the supply chain to prepare for unexpected events, respond to disruptions, and recover from them by maintaining continuity of operations at the desired level of connectedness and control over structure and function” (Ponomarov \& Holcomb, 2009, p. 131). Resilient supply chains are resistant in delaying a disruption and reducing the impact once the disruption occurs, robustly malleable in withstanding disruptions within acceptable degradation parameters, and smoothly effective in recovering within an acceptable time and composite costs and risks (Melnyk et al., 2014; Tukamuhabwa et al., 2015). Nonetheless, SCR is more than a capability deployed reactively, since it enables SC member firms both to resist difficulties and adversities and realize the benefits of various opportunities environment present (Sheffi \& Rice, 2005). Accordingly, SCR enables firms to gain an advantage out of disruptions by positioning better than competitors (Sheffi \& Rice, 2005).

SCR is an indispensable element of holistic risk management strategies and practices. This is true for both pre- and post-management of risks, as SCR enables SC members to prepare and respond to unexpected adverse incidents (Colicchia \& Strozzi, 2012; Ponomarov \& Holcomb, 2009). Thus, even though SCR is an integral component of risk management (Ponomarov \& Holcomb, 2009), its utility reaches beyond the 
purposes of conventional risk management. SCR can also be relevant to marketing, as the firm's and its employees’ resilience influence the way marketing operations are executed, and the way marketing employees feel and behave (Bande et al., 2015). Likewise, recent research points out that resilience can be seen as an increasingly important element of service quality in B2B contexts (Williams et al., 2018).

Leading members of a supply chain are responsible for building resilience in their enterprises and contributing to the resilience of the whole system (Gölgeci \& Ponomarov, 2015; Kamalahmadi \& Parast, 2016). As supply chains are holistic business systems (Tukamuhabwa et al., 2015), resilient capabilities of its members can transform into SCR (Sheffi \& Rice, 2005), as long as member firms make up a coherent entity as a whole and interactions among them are managed and coordinated effectively.

\section{Hypotheses}

\subsection{Social capital, absorptive capacity, and supply chain resilience}

Social capital affects the resource exchange in network relationships as it provides access to tangible and intangible resources, provides opportunities, and facilitates learning (Tsai \& Ghoshal, 1998). Indeed, building firm resources and capabilities rest on the availability of social capital (Tsai \& Ghoshal, 1998; Zahra, 2010). Following this argument, our first hypotheses, H1A and H1B posit the basic linkages between social capital and absorptive capacity, and SCR.

There are various sets of concepts such as organizational compatibility and informational technology (IT) capabilities that are examined as the antecedents of absorptive capacity (e.g., Liu et al., 2013; Saenz et al., 2014). That said, we focus on social capital as a potential antecedent of absorptive capacity with a view of the relational sources of external knowledge. Firms can utilize their social capital to get hold of new business partners and exchange information with them (Inkpen \& Tsang, 2005; Zahra, 2010). Strong structural connections between partners enable dense resource exchange and routines between them (Capaldo, 2007; Lew, Sinkovics, \& Kuivalainen, 2013). For example, trust facilitates smoother information exchanges and makes SC partners to share tacit and valuable knowledge (Inkpen \& Tsang, 2005). In this vein, it is worth noting that absorptive capacity is a dynamic capability that typically grows and is applied in 
interorganizational context for organizational learning and innovation (Najafi-Tavani et al., 2018; Saenz et al., 2014; Tsai, 2001).

Yli-Renko et al. (2001) argue that social capital (i.e., social interaction, network ties, and relationship quality) increases the firm's knowledge acquisition from the firm's relationships as well as the exploitation of this knowledge. Their results support the linkage between social interaction and network ties that confirm frequent interactions facilitate learning, and the higher level of social capital increases the firm's ability to absorb the knowledge. Inkpen and Tsang (2005) also point out that social capital is a significant driver for knowledge acquisition from a firm's relationships and facilitate the transfer of the knowledge further. Thus, social capital and its underlying elements can enable higher success as correctly identifying and acquiring relevant external information to be assimilated and deployed within the firm boundaries.

H1A: A firm's social capital has a positive influence on its absorptive capacity

Long-term SC effectiveness requires trust and mutually beneficial relationships to reduce risk (Johnson et al., 2013). Social capital literature has highlighted trust as a shared cooperative mechanism used to manage conflict between partners (see Lew et al., 2013; Nahapiet \& Ghoshal, 1998). The relational aspect of social capital -i.e., trust and goodwill- make it more likely that resources are shared and exchanged (Nahapiet \& Ghoshal, 1998). If there were unexpected events or disruptions in the supply chain, relational social capital would help the firm to recover from the shock faster as the trusted partners would act benevolently and try to improve the situation and even prioritize the customer with higher social capital. Social capital between SC partners can work as a hedge asset against adversities, spur collective action, and help stay coherent against sudden disruptions (Adger, 2003). The broader network access could also provide firms with alternative supply or distribution routes to allow quick responses to contingencies.

H1B: A firm's social capital has a positive influence on its supply chain resilience.

\subsection{The moderating role of marketing-SCM alignment}

Divergent characteristics, attitudes, and behaviors of employees in marketing and SCM functions can fuel substantial tensions on how boundary-spanning capabilities are deployed to make use of external resources 
(Gölgeci et al., 2019; Jüttner et al., 2010). Therefore, aligning the firm’s formal organizational structure with the distribution and coordination of capabilities to apply resources is a salient challenge with noteworthy potential returns especially across marketing and SCM (Piercy, 2009).

Organizational alignment involves minimizing the divergence of interests between the relevant parties and functions (Ashenbaum et al., 2009; Powell, 1992). In light of this notion, we define marketing-SCM alignment as the extent to which marketing and SCM functions work together harmoniously based on shared objectives and coherent organizational structures. Thus, like other concepts we examine in relation to SCR, alignment is a relational factor. Marketing-SCM alignment epitomizes establishing shared overarching blueprint for value creation, transcending cross-functional tensions, and maintaining a unified structure for a diverse set of marketing and SCM activities. It is, therefore, at the epicenter of the way a firm functions and engages with its partners with a particular purpose (Ashenbaum et al., 2009).

Social capital and absorptive capacity may be ineffectual without goal, structure, and activity alignment across the functions and within the firm (Jüttner et al., 2010). Organizational resources and capabilities can only be bundled effectively if firm objectives are aligned and co-owned by the firm's constituents (Jüttner et al., 2010). Alignment and congruence of marketing and SCM with one another are instrumental in jointly leveraging resources and capabilities embedded within and across organizational boundaries (Piercy, 2009). In contrast, misalignment can lead to tensions and disorientation due to different organizational forces pulling in different directions that could hurt the firms' integrity and relational position (Gölgeci et al., 2019). Boundary-spanning managers may have little chance to apply and utilize their firms’ aggregate social capital to foster absorptive capacity if marketing and SCM do not work well together (Heracleous \& Werres, 2015).

We expect that marketing-SCM alignment can enhance the influence of social capital on absorptive capacity. Utilizing external information stemming from SC partners and executing it to make necessary decisions entail unified mindset and aligned processes (Ashenbaum et al., 2009). Given its nature and main benefits discussed above, marketing-SCM alignment can function as a catalyst in transforming social capital into absorptive capacity. Firms that align and unify their organizational structures and activities can be 
effective in orchestrating their supply chains and managing knowledge embedded in these networks (Möller \& Svahn, 2003). In particular, organizational processes of assimilation and transformation of external knowledge gained by social capital require shared practices and coordination between the firm's marketing and SCM functions even if alignment may not be fundamental to initial acquisition of exploratory knowledge (Mom et al., 2015). Accordingly, external information can be best coded and decoded into knowledge when firms’ organizational functions and processes are aligned. As many firms have to deal with competing priorities and business practices within and across their boundaries (Gölgeci et al., 2019; Jüttner et al., 2010), marketing-SCM alignment could be pivotal in leveraging potential synergies between social capital and absorptive capacity. Misalignment can derail the utilization of social capital for learning purposes by widening the gap between the external environment and the firm's strategy and processes (Heracleous \& Werres, 2015).

H2A: Marketing-SCM alignment strengthens the influence of social capital on absorptive capacity.

When it comes to SCR, social capital boosts exchanges between the SC partners in ways that support their respective goals. Marketing-SCM alignment can make a firm more efficient in using its social capital to respond to shocks in its supply chain, and this could again relate to better coordination between the firm and its SC partners (cf. Möller \& Svahn, 2003). It may be that cooperation is rewarded within the firm and among the SC partners in times of uncertainties and difficulties. If this is a case, this provides an incentive and strengthens the relationship between social capital and SCR. Christopher and Lee (2004) suggest that a key to improved SC visibility is shared information among SC members and the risks relate more to changes in the firms' business strategy. Marketing-SCM alignment would positively moderate the relationship between social capital and SCR, because the entity as a whole could give a more unified response to the SC partners, due to shared norms for and incentives to work together. Firms with aligned marketing and SCM functions and harmonized workforce are likely to tap relational resources more effectively to respond to adverse change than firms with misaligned functions. Moreover, aligned marketing and SCM functions with integrative social mechanisms can develop more coherent intra- and interorganizational activity 
structure fostering trust and goodwill (Stolze et al., 2015), which would make its supply chain more resilient (Gölgeci \& Ponomarov, 2015).

H2B: Marketing-SCM alignment strengthens the influence of social capital on supply chain resilience.

\subsection{The mediating role of absorptive capacity}

One of the primary elements that keep supply chains resilient is the nature of relationships between SC partners reflected in cohesiveness among them. Collaborative partnerships help manage risks and disruptions effectively (Adger, 2003; Johnson et al., 2013). Strong relationships and joint information and resource allocation are needed to uphold cohesion across firm boundaries (Borgatti \& Halgin, 2011) to endure hardships and remain intact in the wake of adversities. Likewise, firms running collaborative interorganizational relationships are better equipped against SC disruptions (Johnson et al., 2013).

Uncertainty and the lack of information cloud judgment, and firms need knowledge of the external environment to navigate their activities and sustain their existence. Thus, absorptive capacity could serve as a critical driver of SCR by enabling the success of acquiring, assimilating, transforming, and exploiting external information (Zahra \& George, 2002). The presence of absorptive capacity is required to turn collaborative relationships into positive outcomes (Najafi-Tavani et al., 2018). Firms and their supply chain could leverage their absorptive capacity to acquire and utilize knowledge against unexpected or sustained difficulties. Furthermore, absorptive capacity could be critical for putting knowledge for innovative use (Najafi-Tavani, Sharifi, \& Ismail, 2013) against disruptions and adversities that have been shown to enable SCR (Gölgeci \& Ponomarov, 2015). Recent research has found that absorptive capacity enhances the ability to effectively mitigate SC risks that can jeopardize SCR (Ambulkar et al., 2016). In this vein, knowledge and understanding of SC structures (physical, relational, and intangible), which could be harnessed via absorptive capacity (Tsai, 2001), can be considered essential enablers of SCR. We argue that absorptive capacity can function as an essential enabler of SCR.

H3: A firm's absorptive capacity has a positive influence on its supply chain resilience. 
Though extant research has traditionally emphasized the benefits of relationships (Dyer \& Singh, 1998), recent research acknowledges that interorganizational relationships can have both positive and negative consequences (Mitręga \& Zolkiewski, 2012). Accordingly, social capital does not automatically result in wanted performance outcomes. Deploying absorptive capacity can help firms achieve positive outcomes from social capital. Therefore, as a potential stock of tangible and intangible relational assets, social capital may require the mediating means of absorptive capacity to channel its potential impact on SCR.

The relevance of absorptive capacity as a mediating mechanism stems from its function of acquiring, assimilating, transforming, and exploiting pertinent external information (Zahra \& George, 2002). Absorptive capacity functions as a conduit between the firms' interorganizational relationships and the strategic internal leverage of external knowledge (Najafi-Tavani et al., 2018). Accordingly, if the firm does not possess absorptive capacity, it may not reap the benefits of social capital to a fuller extent. Though social capital means social access to resources like crucial information (Borgatti \& Halgin, 2011), such information needs to be acquired and processed through absorptive capacity to be applied toward useful ends of recovering in the aftermath of external shock and staying intact against uncertainty and adversity. It needs to go through processes underpinned by absorptive capacity to turn into knowledge that foster SCR.

Absorptive capacity facilitates knowledge flow in supply chains (Tsai, 2001), and it can enable alertness to sudden changes, keep communication channels open during external shocks, and leverage firms' knowledge-related social capital to weather SC disruptions. It aids real-time understanding of unexpected changes, enables making sense of implications of environmental change and associated opportunities, and provides knowledge tools for tackling disruptions at the time they occur (Van Doorn et al., 2017) for enhancing SCR. In this vein, absorptive capacity can be considered as a means of engaging in knowledge development activities, thereby enhancing a firm's ability to manage SC risks (Ambulkar et al., 2016). Absorptive capacity can, therefore, transform insights and information obtained in supply chains into instrumental ingredients for withstanding adversities and tackling disruptions. 
Absorptive capacity can also alleviate dark elements ingrained in social capital. For example, if social capital is coupled with dysfunctional identification processes, it can restrict the processing of information (Pillai et al., 2017). Thus, firms can utilize their absorptive capacity to resolve information processing gridlocks and weed out harmful elements in social capital that obscure knowledge flow within supply chains (Xiong \& Bharadwaj, 2011). If the firm cannot obtain, process, and digest unique and valuable information derived from its partners, mere social access to such information cannot make a difference when facing sudden disruption or sustained adversity. The firm must be able to link its knowledge to its operations in a meaningful way (Najafi-Tavani et al., 2013), if it wants to survive challenges. Accordingly, firms need not only the opportunity to access the resources provided by interorganizational relationships but also the ability to utilize them through the complementary capability of absorptive capacity (Xiong \& Bharadwaj, 2011).

H4: A firm's absorptive capacity mediates the link between social capital and supply chain resilience.

\subsection{Supply chain resilience and organizational performance}

Despite an extensive research on SCR and abundant evidence on its importance (Kamalahmadi \& Parast, 2016; Linnenluecke, 2017; Pettit et al., 2013; Ponomarov \& Holcomb, 2009; Sheffi \& Rice, 2005), the link between SCR and organizational performance has received relatively lesser attention (Mccann et al., 2009). The potential reason behind the lack of interest in the outcomes of SCR could partially be due to a perspective adopted by some SCM scholars that views SCR as an outcome variable on its own (e.g., Btandon-Jones et al., 2014; Pettit et al., 2013). This line of research assumes that SCR can be seen as a dimension of performance with a specific emphasis on longevity and survival of the firms and supply chains. Nonetheless, this assumption is not always shared by researchers that view SCR as a capability (Gölgeci \& Ponomarov, 2015; Ponomarov \& Holcomb, 2009).

The divergent perspectives on SCR and its role in performance outcomes motivate examining the potential role of SCR in organizational performance to better understand its value and relevance to firms operating amid increased uncertainty and volatility. While we view SCR as an adaptive capability and acknowledge potential costs and tradeoffs involved in building SCR (Pettit, Fiksel, \& Croxton, 2010), we 
expect that SCR can have a positive impact on organizational performance. Past research argues that resilience, in general, enables firms to take situation-specific, robust, and transformative actions when confronted with unexpected and severe adverse events that can jeopardize the firm's long-term survival, and thus, resilience emerges as a pivotal prerequisite for thriving in a dynamic environment (Lengnick-Hall \& Beck, 2009). Likewise, Mccann et al. (2009) find that resilience is positively associated with firm competitiveness and profitability. In specific, resilient practices within the SCM domain is found to play a positive role in customer satisfaction as a performance outcome (Govindan et al., 2015). Furthermore, the essence of SCR as an ability of the firm to return to its original state or a new, more desirable state after facing SC disruptions (Ponomarov \& Holcomb, 2009) signals potential positive performance outcomes of SCR. Thus, in light of theoretical arguments and relevant empirical evidence, SCR could be expected to play an overall positive role in enhancing the firms’ performance and competitiveness.

H5: A firm's supply chain resilience has a positive influence on its organizational performance. The conceptual model of our paper is presented in Fig. 1.

\section{[Insert Fig. 1]}

\section{Methods}

\subsection{Sampling and data collection}

In this research, we chose Turkey as a research context, because firms located in Turkey often face a high degree of turbulence, adverse conditions, and uncertainties. Volatility, uncertainty, and adversity in Turkey stem both from external and internal sources. External sources include regional volatilities and conflicts. In particular, Turkey's strategic yet volatile geopolitical location is both a blessing and a curse for businesses in Turkey. Such location means unique business opportunities to serve Europe, Asia, and Africa. However, Turkey also sits at the epicenter of a much contended and hostile region characterized by high levels of adversity and turmoil that amplifies the risks and uncertainties involved in doing business.

Internal sources of uncertainty and turbulence include sociopolitical instability in Turkey. For example, at the time of data collection (late 2013 and early 2014) for the current study, Turkey was just reeling from 
the recent Gezi Park protests. These protests, the Syrian civil war that was heating up at the time of data collection, and its fallout in Turkey contributed to ensuing political strife and economic hardships Turkey has recently been experiencing. These recent factors amplify the importance of SCR in the Turkish context. Furthermore, Turkish firms inherit rich and diverse social and political atmosphere with the high importance of social networks and capitals from those networks (Cetindamar et al., 2012), which foster the relevance of Turkish context for studying behavioral and relational elements underpinning SCR. Thus, we believe Turkey is a relevant context to conduct our research on SCR.

We designed our survey following survey design procedures suggested by Podsakoff et al. (2003). To assist in the preparation of the survey, we validated the content through a series of interviews with five academic and two practitioner experts on its different sections. We then pre-tested the survey using 12 executives acting as both respondents and reviewers to the second version of the survey. Their suggestions were incorporated into the third and final version of the survey, but their answers were omitted from the final sample. The survey was administered in the Turkish language, the English language original having been translated into Turkish by the first author and back-translated into English by a translator. To further ensure the veracity of the translation, two bilingual researchers compared the backtranslated English and Turkish versions of the survey and made any necessary changes.

In Turkey, we focused on sampling several product-intensive industries to achieve sufficient levels of local external validity (Cook \& Campbell, 1979) and generalizability. The sampling frame of the research was based on the registry of The Union of Chambers and Commodity Exchanges of Turkey (TOBB), and we targeted randomly selected 1000 firms that met our selection criteria among $>40,000$ firms registered within TOBB’s 93 chambers. Targeted respondents across these firms were those high and mid-level managers that have inclusive responsibilities that enable them to have an accurate understanding and a complete view of the firm strategy and functioning.

Given the requirements of the nature of research inquiry and to alleviate common method variance (CMV) (Chang, Van Witteloostuijn, \& Eden, 2010; Podsakoff et al., 2003), dual respondents from each 
participant firm were required to be included in the final analysis. Furthermore, gathering dual respondents from participant firms could foster the accuracy of data collected on marketing-SCM alignment as an essential moderator, because having dual respondents with complementary perspectives enables understanding organizational dynamics better than having one respondent. We received 530 full responses from 265 firms with an effective response rate of $26.5 \%$, which was deemed adequate for our research. Although a total of 376 firms returned the surveys, only 265 returned the full surveys with dual responses. Comparing answers of two respondents for each firm yielded high consistency and equivalence regarding means and properties of perceptual measures across two respondents within each firm. Following the assessment of consistency and equivalence, we merged responses of two key informants in each firm by taking an average of these responses to arrive a firm-level unit of analysis. The characteristics of the sample firms are summarized in Table 1.

\section{[Insert Table 1]}

We addressed potential non-response bias during data collection process through several means. First, relatively high response rate (26.5\%) indicated that respondents were likely to constitute a reasonable level of representativeness of the total sample base utilized in this research and remedy potential non-response bias (Rose, Sidle, \& Griffith, 2007). Second, an independent t-test to compare the responses of early and late respondents did not reveal any significant differences concerning respondents' demographic information such as annual sales volume, number of employees, and firm age as well as the relevant variables tested in this research (Rogelberg \& Stanton, 2007).

\subsection{Measurement}

We used the existing validated scales for measuring social capital (Acquaah, 2007; Zahra, 2010), absorptive capacity (Flatten et al., 2011), marketing-SCM alignment (Ashenbaum et al., 2009; Chen, Mattioda, \& Daugherty, 2007), SCR (Gölgeci \& Ponomarov, 2015), and organizational performance (Collings et al., 2010; Demirbag et al., 2014). All the variables in our model were Likert measurement scales with anchor values of 1 to 7 . Cronbach $\alpha$ scores of scales are provided in Table 2. 
Finally, we included firm age as number of years the participant firm operates and firm size as the participant firm's number of employees in our analyses. Firm age was included to test whether older firms have more absorptive capacity, have higher SCR, and perform better than the younger ones. Likewise, firm size was included to test whether it accounts for some of the variations in absorptive capacity, SCR, and organizational performance. Table 2 contains the used items and data sources for the measures.

\section{[Insert Table 2]}

\section{Analysis and results}

\subsection{Reliability and validity}

The means, standard deviations, coefficient alpha reliability estimates and correlation coefficients for all the variables appear in Table 3. As a first step toward establishing reliability and validity, we followed both preand post-data collection measures to remedy the potential CMV threat as suggested by Podsakoff et al. (2003). We first pre-tested survey items for clarity, and we assured research participants' anonymity, to alleviate item characteristic effects. When designing the survey, we made sure that the indicators for the different concepts appeared in different parts of the survey, which should diminish the possibility of CMV, item context effects, and some of the measurement context effects (Podsakoff et al., 2003). Furthermore, multiple qualified informants for each participating firm that completed the survey contributed to the consistency of the responses. Following the data collection, a single-common-method factor was applied to account for the possibility of common influence across all responses as assessed by Harman's one-factor test for CMV using CFA, comparing a single-factor model with the original measurement model. Results revealed that the model single-factor had a significantly worse fit $(\Delta \chi 2=726.149 ; \Delta d f=10 ; p<0.001)$. No single factor is found to explain more than $50 \%$ of the variance. Additionally, we performed common latent factor (CLF) analysis (Podsakoff et al., 2003). The pattern and significance of the paths do not change when we include a CLF in the model, and none of the differences between standardized regression weights of respective paths in the models with and without CLF was above 0.08 , which is below the 
recommended threshold of 0.2. Based on these analyses, CMV was not deemed to be a threat to the validity of the research (Podsakoff et al., 2003).

\section{[Insert Table 3]}

To estimate construct validity, we ran a CFA measurement model. The measurement model results indicate a good model fit: $(\chi 2(276)=402.40, \mathrm{p}<0.001 ; \mathrm{NFI}=0.916 ; \mathrm{IFI}=0.972 ; \mathrm{TLI}=0.967 ; \mathrm{CFI}=0.972$; RMSEA=0.042). Moreover, for all constructs, the average variance extracted (AVE) estimates and composite reliability (CR) were above the recommended thresholds of 0.5 and 0.7 , respectively, which indicates convergent validity (Bagozzi \& Yi, 2012). We evaluated discriminant validity by applying a procedure by Fornell and Larcker (1981), which showed that for all constructs the AVE values were higher (Table 4) than the shared variances. Together, the results of these analyses confirm discriminant validity.

We also calculated the variance inflation factor (VIF) to address potential multicollinearity issues. Our analysis shows that the measures do not pose a multicollinearity problem, since the values are well below the conservative recommended threshold of 4 (Pan \& Jackson, 2008). Additional exploratory factor analysis indicates that all item loadings are above the recommended cut-off value of 0.6 (Bagozzi, Yi, \& Phillips, 1991), and none of the items cross-loaded on other factors.

\section{[Insert Table 4]}

\subsection{Hypotheses testing}

Our study is based on the theoretical model depicted in Figure 1. We tested the hypothesized relationships by estimating a structural equation model (SEM) in AMOS 25. SEM offers several advantages relevant to our research. SEM is a very comprehensive technique aimed at the analysis of latent variables and their relationships (Anderson \& Gerbing, 1988). SEM also can analyze time series data and test non-normal data. As the majority of variables in our framework are latent and we test mediation and moderation effects within the whole model, the SEM procedure was considered suitable for our analyses.

First, we tested the direct and moderating paths and then the mediating role of absorptive capacity. Given that we applied interaction terms in the model, we used single-indicant estimation method to calculate 
them. We mean-centered the constructs to mitigate the multicollinearity problem and used Ping's (1995) equations to estimate the loadings and error variances of the product terms. We also controlled for firm size and firm age in relation to absorptive capacity, SCR, and organizational performance to account for potential firm heterogeneity effects and enhance the analytical rigor. The fit statistics for the structural model are well within generally accepted limits $(\chi 2(349)=516.32, \quad \mathrm{p}<0.001 ; \mathrm{NFI}=0.898 ; \mathrm{IFI}=0.964, \mathrm{TLI}=0.958$; $\mathrm{CFI}=0.964 ;$ RMSEA $=0.043$ ) and indicate a good fit to the data. Table 5 shows the standardized parameter estimates and the directional significance levels for the investigated structural paths.

\section{[Insert Table 5]}

5.2.1 Direct effects and moderation. In $\mathrm{H} 1 \mathrm{~A}$ and $\mathrm{H} 1 \mathrm{~B}$, we argue that social capital is associated positively with absorptive capacity and SCR. The results support these hypotheses $(\beta=0.57 ; t=5.23 ; p<0.001 ; \beta=0.59$; $\mathrm{t}=4.82 ; \mathrm{p}<0.001$, respectively). In $\mathrm{H} 5$, we expect that SCR is positively associated with organizational performance. In support of our hypothesis, the path between SCR and organizational performance is significant $(\beta=0.50 ; \mathrm{t}=5.44 ; \mathrm{p}<0.001)$

Our findings also demonstrate that the effect of social capital on SCR is contingent upon marketingSCM alignment. Specifically, we argue in H2A that marketing-SCM alignment strengthens the relationship between social capital and absorptive capacity, and our findings ( $\beta=0.13$; $\mathrm{t}=3.14 ; \mathrm{p}<0.01$ ) provide support for this hypotheses. H2B that posits marketing-SCM alignment strengthens the link between social capital and SCR is also supported $(\beta=0.10 ; \mathrm{t}=2.19 ; \mathrm{p}<0.05)$.

Following Aiken and West (1991), we plotted the relationships between social capital and absorptive capacity under high and low (one standard deviation above and below the mean) levels of marketing-SCM alignment to illustrate interaction effects. As shown in Fig. 2, marketing-SCM alignment changes the strengths of the links between social capital and absorptive capacity and social capital and SCR. This result means that social capital can be a better supporting asset to absorptive capacity and SCR in a stronger way when firms' functions are aligned and work harmoniously.

\section{[Insert Fig. 2]}


5.2.2 Mediation. Mediation analysis is employed to offer a more refined explanation of serial linkages by illustrating how, or why, an independent factor influences a dependent variable (Hair et al., 2010). To test mediation, we started with testing the direct linkages between absorptive capacity and SCR. Absorptive capacity is also significantly associated with $\operatorname{SCR}(\beta=0.31 ; \mathrm{t}=3.58$; $\mathrm{p}<0.001)$, indicating support for $\mathrm{H} 3$.

We then used the bootstrapping method suggested by Preacher and Hayes (2008). We analyzed indirect effects by setting the number of sampling iterations (N) to 5000. When testing the mediating effect of absorptive capacity, the direct effects between social capital and SCR were found to be significant at $\mathrm{p}<0.001$ both with and without the mediation. Moreover, the bootstrapping method revealed that the indirect effect of social capital on SCR through absorptive capacity was significant at $\mathrm{p}<0.001$. This result points to a partial mediation and supports $\mathrm{H} 4$.

\section{Discussion and conclusions}

\subsection{Theoretical contributions}

Firms operate in increasingly hostile and disruptive environments that are formidable to deal with by relying solely on internal resources and strategies. Under these circumstances, firms’ social capital derived from their network ties could offer unique resources to be utilized against adversities and disruptions and an alternative route to SCR. However, little is known how and when social capital leads to SCR. This issue also highlights the insufficient attention paid to investigating the in-depth picture of antecedents and consequences of SCR. It also brings out our central premise that absorptive capacity and marketing-SCM alignment can play an instrumental role in explaining how firms can utilize social capital for the resilience of their supply chains and improve their organizational performance.

Our findings suggest that absorptive capacity can function as a linking pin between social capital and SCR and explain how social capital can be used to develop SCR. Because social capital is a vital yet operand resource -a stock of relational assets- (Nahapiet \& Ghoshal, 1998), operant boundary-spanning capability of absorptive capacity are required to channel it toward strategic ends so as to realize its potential and manifest its influence on SCR. This finding advances the extant research on the antecedents of SCR that examine its 
immediate drivers but overlook mediating mechanisms that serve as a conduit between intangible external resources and SCR (Kamalahmadi \& Parast, 2016; Linnenluecke, 2017; Pettit et al., 2013).

Our research also reveals that the role of social capital and absorptive capacity in SCR can be contingent upon marketing-SCM alignment, which gives an account to the when the question of the linkages between social capital, absorptive capacity, and SCR. Marketing-SCM alignment is needed to effectively leverage absorptive capacity to make the best use of social capital in developing SCR. Likewise, marketingSCM alignment strengthens the direct role of social capital in SCR. The alignment process of the firm can include developing integrative objectives for the whole supply chain, evaluating performance based integrative objectives, rewarding cooperation, and synchronizing in cross-functional teams. Overall, the role of marketing-SCM alignment is highlighted as a contextual basis shaping the success in capitalizing on interorganizational resources through absorptive capacity. This finding is in line with and adds to the research that examines capabilities as forces embedded in their organizational contexts (Trentin et al., 2015).

Our paper makes three distinct contributions to marketing and SCM research. First, we contribute to inquiries on how firms leverage network-based resources to endure adversities and disruptive change and to maintain providing relevant value to their customers and stakeholders. Empirical research on the antecedents of SCR or other forms of resilience focuses on the role of either resources or capabilities (Aldrich, 2012; Aldrich \& Meyer, 2015; Gölgeci \& Ponomarov, 2015) but rarely their joint influence (Johnson et al., 2013) and not in theory testing fashion. Our research examines how the strategic relational resource of social capital is put into use through absorptive capacity to materialize its potential role in SCR. Our findings on the role of social capital as a relational source of SCR complements extant research on other enablers of SCR such as IT (Mikalef \& Pateli, 2017; Vanpoucke, Vereecke, \& Muylle, 2017; Wu et al., 2006) as technological sources of SCR. Our findings vis-à-vis existing literature on the role of IT highlights the notion that the drivers and enablers or SCR are likely to be more multifaceted and holistic than unidimensional and narrow-scoped. 
Second, we suggest that the alignment between marketing and SCM, two essential boundary-spanning functions (Piercy, 2009), can be a critical contingency for synergistic deployment and utilization of absorptive capacity for SCR. We stress that the application and utilization of capabilities cannot be separated from marketing-SCM alignment. The inclusion of marketing-SCM alignment into the picture develops a contingent view of the role social capital plays in SCR through mediating capability of absorptive capacity. On the contrary, the cases of WorldCom and Nortel Networks show that strategic misalignments of crucial organizational functions like marketing and SCM amplify the gap between the demands of the competitive environment and the organization's strategy and competencies, leading to failure and ultimate demise (Heracleous \& Werres, 2015). The bankruptcies of these two large firms and others highlight that marketingSCM alignment cannot be taken lightly in the pursuit of SCR. In other words, these examples and our findings indicate that marketing-SCM alignment is a pivotal condition for SCR and organizational survival, firms face a higher possibility of failure if they do not align their strategic functions like marketing and SCM. Our findings and the cases of WorldCom and Nortel Networks underscore entwinement between absorptive capacity and marketing-SCM alignment regarding the use of absorptive capacity in rapidlychanging turbulent contexts. Putting these two contributions together can explain why some firms might have low SCR while possessing higher levels of social capital and vice versa and help resolve inconsistent findings in research on social capital and resilience.

Third, past research has predominantly assumed SCR as a critical capability in volatile and turbulent environments (Btandon-Jones et al., 2014; Gölgeci \& Ponomarov, 2015; Lengnick-Hall \& Beck, 2009; Mccann et al., 2009; Ponomarov \& Holcomb, 2009), but paid scant attention to whether the assumption on the value of SCR for the firm withstand empirical scrutiny (Govindan et al., 2015). We move beyond a mere supposition that SCR is essential for firm performance and empirically test whether SCR leads to increased organizational performance. Our findings provide empirical support to the argument that SCR can underlie positive outcomes and substantiate claims that SCR upholds superior organizational performance amid uncertainty and volatility. 


\subsection{Practical implications}

The findings of this study have two major managerial implications for firms that aim to build SCR and achieve higher performance in turbulent environments. The first is to capitalize on the firm's social capital through absorptive capacity. Most firms have valuable resources embedded in their interorganizational relationships. However, some of these crucial resources can stay dormant if they are not tapped against risks and adversities. Thus, firms should develop and activate their absorptive capacity to capitalize on their social capital in the pursuit of SCR. Though financial and behavioral investments in absorptive capacity are required to develop, maintain, and utilize it, it can play an important role against adversities in the long run.

Second, we highlight that marketing-SCM alignment facilitates realizing the potential of social capital and absorptive capacity for SCR. As corporate bankruptcy rates have soared due to organizational failures that are brought about by strategic misalignments (Heracleous \& Werres, 2015), the role of marketing-SCM alignment in firm survival is increasingly becoming visible. Thus, firms should employ needed measures to ensure aligned structure and behavior to use their social capital in times of difficulties and achieve SCR. Alignment is not a clear-cut or unidimensional phenomenon. Firms may face paradoxical choices in their journey of cultivating and preserving the alignment of their processes and structure due to competing priorities of different functions (Jüttner et al., 2010). It is, nonetheless, advantageous to maintain organizational cohesion and harmony to be able to achieve SCR through the resources embedded in the firms' relationships. Firms that have shared objectives, cross-functional collaboration, and coherent and integrated activity patterns (and systems such as IT) are likely to be in a better position to effectively manage and leverage their supply chains to stay resilient for improved performance.

\subsection{Future research}

This research offered a relationships based view of SCR. We posit that resources obtained through interorganizational relationships can be an important source of SCR. However, a more nuanced and in-depth approach is needed to truly appreciate how such resources can be utilized to support firms against hardships and turbulence they face in the current business environment (Pettit et al., 2013). For example, there might 
be the disparity between the perception and the reality of social capital, and it is not clear how such disparity could influence SCR. Thus, future research can explore the role of subtle dimensions and aspects of social capital in firms' responses to disruptions and adversities. Likewise, future research can expand upon our findings and explore the role of other network related forces such as network structure, network dynamics, brokerage, and structural holes in SCR (Borgatti \& Halgin, 2011).

Other further research could focus, for example, on the role firms play in supply chains. The role is very much related to the governance of the value chain (cf. Mentzer et al., 2008) and we assume that, for example, in captive relationships where a supplier is very dependent on the lead firm (a buyer) resilience may be difficult to establish. However, when the firm's position in the supply chain is central, other parties might be eager to help that firm in the times of adversity for their survival. When we would gain more confidence in our knowledge of the determinants of SCR based on empirical testing, the next logical step would be to develop more detailed managerial and organizational processes associated with SCR. Some areas to look at would be e.g., how to effectively integrate, coordinate and control global supply chain relationships with local suppliers, a critical task to enhance competitiveness in general, and where IT integration could help along ‘classic’ trust building mechanisms (cf. Sinkovics et al., 2011; Vanpoucke et al., 2017). In this, we hope our model provides a useful base.

Furthermore, as the majority of extant research on the antecedents of SCR focuses on positive drivers and enablers, there is a need to explore what factors could obstruct or deter SCR. For example, there is a need to delve deeper into internal (such as organizational structure) and external (such as network fluidity) factors that may hinder firms’ long-term survival and resilience. The examination of such overlooked negative factors could help advance the knowledge on SCR as it could offer new perspectives to the development, deployment, and conservation of SCR.

Our research took place in the emerging market of Turkey. Prospective research can, accordingly, scrutinize SCR in developed vs. emerging markets especially in terms of macro factors and network effects, which would enable further explaining the boundary conditions and underpinnings of the linkage between 
SCR and its antecedents and consequences. This can provide valuable insight into the B2B marketing literature whether SCR research conducted in developed markets can be applied in developing countries, and how SCR is developed and manifested across national borders.

Finally, from a methodological standpoint, research on SCR can benefit from methodologies beyond commonly adopted methods of case studies and survey-based research. For example, qualitative comparative analysis (QCA) allows a more thorough understanding of how different combinations of conditions/configurations lead to a specific outcome and the possibility that different paths produce the same outcome (Tóth, Henneberg, \& Naudé, 2017). Thus, in contemporary markets of unprecedented complexity and dynamism, QCA can be adopted to explore different alternative routes or configurations to achieve SCR, as it enables researchers to account for the asymmetrical and interactive nature of underlying forces behind SCR. Resilience is an increasingly important and sophisticated phenomenon that benefit from a wide range of substantive, theoretical, and methodological approaches, and it can considerably enrich our understanding of B2B marketing in the current disruptive age. 


\section{References}

Acquaah, M. (2007). Managerial social capital, strategic orientation, and organizational performance in an emerging economy. Strategic Management Journal, 28(12), 1235-1255.

Adger, W.N. (2003). Social capital, collective action, and adaptation to climate change. Economic Geography, 79(4), 387-404.

Aiken, L.S., \& West, S.G. (1991). Multiple regression: Testing and interpreting interactions. Newbury Park, CA: Sage.

Aldrich, D.P. (2012). Building resilience: Social capital in post-disaster recovery: University of Chicago Press.

Aldrich, D.P., \& Meyer, M.A. (2015). Social capital and community resilience. American Behavioral Scientist, 59(2), 254-269.

Ambulkar, S., Blackhurst, J.V., \& Cantor, D.E. (2016). Supply chain risk mitigation competency: An individual-level knowledge-based perspective. International Journal of Production Research, 54(5), 1398-1411.

Anderson, J.C., \& Gerbing, D.W. (1988). Structural equation modeling in practice: A review and recommended two-step approach. Psychological Bulletin, 103(3), 411-423.

Ashenbaum, B., Maltz, A., Ellram, L., \& Barratt, M.A. (2009). Organizational alignment and supply chain governance structure: Introduction and construct validation. International Journal of Logistics Management, 20(2), 169-186.

Astley, W.G., \& Sachdeva, P.S. (1984). Structural sources of intraorganizational: Power: A theoretical synthesis. Academy of Management Review, 9(1), 104-113.

Bagozzi, R.P., \& Yi, Y. (2012). Specification, evaluation, and interpretation of structural equation models. Journal of the Academy of Marketing Science, 40(1), 8-34.

Bagozzi, R.P., Yi, Y., \& Phillips, L.W. (1991). Assessing construct validity in organizational research. Administrative Science Quarterly, 36(3), 421-458.

Bande, B., Fernández-Ferrín, P., Varela, J.A., \& Jaramillo, F. (2015). Emotions and salesperson propensity to leave: The effects of emotional intelligence and resilience. Industrial Marketing Management, 44, 142-153.

Batt, P.J. (2008). Building social capital in networks. Industrial Marketing Management, 37(5), 487-491.

Borgatti, S.P., \& Halgin, D.S. (2011). On network theory. Organization Science, 22(5), 1168-1181.

Btandon-Jones, E., Squire, B., Autry, C., \& Petersen, K.J. (2014). A contingent resource-based perspective of supply chain resilience and robustness. Journal of Supply Chain Management, 50(3), 55-73.

Capaldo, A. (2007). Network structure and innovation: The leveraging of a dual network as a distinctive relational capability. Strategic Management Journal, 28(6), 585-608.

Cetindamar, D., Gupta, V.K., Karadeniz, E.E., \& Egrican, N. (2012). What the numbers tell: The impact of human, family and financial capital on women and men's entry into entrepreneurship in turkey. Entrepreneurship \& Regional Development, 24(1-2), 29-51.

Chang, S.-J., Van Witteloostuijn, A., \& Eden, L. (2010). From the editors: Common method variance in international business research. Journal of International Business Studies, 41(2), 178-184.

Chen, H., Mattioda, D.D., \& Daugherty, P.J. (2007). Firm-wide integration and firm performance. International Journal of Logistics Management, 18(1), 5-21.

Chen, X.-P., Liu, D., \& Portnoy, R. (2012). A multilevel investigation of motivational cultural intelligence, organizational diversity climate, and cultural sales: Evidence from us real estate firms. Journal of Applied Psychology, 97(1), 93-106.

Christopher, M., \& Lee, H. (2004). Mitigating supply chain risk through improved confidence. International Journal of Physical Distribution \& Logistics Management, 34(5), 388-396.

Colicchia, C., \& Strozzi, F. (2012). Supply chain risk management: A new methodology for a systematic literature review. Supply Chain Management: An International Journal, 17(4), 403-418.

Collings, D.G., Demirbag, M., Mellahi, K., \& Tatoglu, E. (2010). Strategic orientation, human resource management practices and organizational outcomes: Evidence from turkey. The International Journal of Human Resource Management, 21(14), 2589-2613.

Cook, T.D., \& Campbell, D.T. (1979). Quasi-experimentation: Design and analysis for field setting. Boston, MA: Houghton Mifflin Company. 
Corvellec, H., \& Hultman, J. (2014). Managing the politics of value propositions. Marketing Theory, 14(4), 355-375.

Delbridge, R. (2007). Explaining conflicted collaboration: A critical realist approach to hegemony. Organization Studies, 28(9), 1347-1357.

Demirbag, M., Collings, D.G., Tatoglu, E., Mellahi, K., \& Wood, G. (2014). High-performance work systems and organizational performance in emerging economies: Evidence from MNEs in Turkey. Management International Review, 54(3), 325-359.

Dyer, J.H., \& Singh, H. (1998). The relational view: Cooperative strategy and sources of interorganizational competitive advantage. Academy of Management Review, 23(4), 660-679.

Flatten, T.C., Engelen, A., Zahra, S.A., \& Brettel, M. (2011). A measure of absorptive capacity: Scale development and validation. European Management Journal, 29(2), 98-116.

Fornell, C., \& Larcker, D.F. (1981). Evaluating structural equation models with unobservable variables and measurement error. Journal of Marketing Research, 18(1), 39-50.

Geng, R., Mansouri, S.A., Aktas, E., \& Yen, D.A. (2017). The role of guanxi in green supply chain management in Asia's emerging economies: A conceptual framework. Industrial Marketing Management, 63, 1-17.

Govindan, K., Azevedo, S.G., Carvalho, H., \& Cruz-Machado, V. (2015). Lean, green and resilient practices influence on supply chain performance: Interpretive structural modeling approach. International Journal of Environmental Science and Technology, 12(1), 15-34.

Gölgeci, I., Karakas, F., \& Tatoglu, E. (2019). Understanding demand and supply paradoxes and their role in business-to-business firms. Industrial Marketing Management, 79, 169-180.

Gölgeci, I., \& Ponomarov, S.Y. (2015). How does firm innovativeness enable supply chain resilience? The moderating role of supply uncertainty and interdependence. Technology Analysis \& Strategic Management, 27(3), 267-282.

Hair, J., Black, W., Babin, B., \& Anderson, R. (2010). Multivariate data analysis - a global perspective (7th ed.). Upper Saddle River, NJ: Pearson Prentice Hall.

Heracleous, L., \& Werres, K. (2015). On the road to disaster: Strategic misalignments and corporate failure. Long Range Planning, 29(4), 491-506.

Hollnagel, E., \& Fujita, Y. (2013). The Fukushima disaster - systemic failures as the lack of resilience. Nuclear Engineering and Technology, 45(1), 13-20.

Hung, H.-M. (2010). Reconciling the paradox of supply-side and demand-side strategies in industrial innovation. Industrial Marketing Management, 39(2), 342-350.

Inkpen, A.C., \& Tsang, E.W.K. (2005). Social capital, networks, and knowledge transfer. Academy of Management Review, 30(1), 146-165.

Jackson, L., \& Young, L. (2016). When business networks "kill” social networks: A case study in Bangladesh. Industrial Marketing Management, 58, 148-161.

Johnson, N., Elliott, D., \& Drake, P. (2013). Exploring the role of social capital in facilitating supply chain resilience. Supply Chain Management: An International Journal, 18(3), 324-336.

Jüttner, U., Christopher, M., \& Godsell, J. (2010). A strategic framework for integrating marketing and supply chain strategies. International Journal of Logistics Management, 21(1), 104-126.

Kamalahmadi, M., \& Parast, M.M. (2016). A review of the literature on the principles of enterprise and supply chain resilience: Major findings and directions for future research. International Journal of Production Economics, 171, 116-133.

Laine, I., \& Galkina, T. (2017). The interplay of effectuation and causation in decision making: Russian SMEs under institutional uncertainty. International Entrepreneurship and Management Journal, 13(3), 905-941.

Lengnick-Hall, C.A., \& Beck, T.E. (2009). Resilience capacity and strategic agility: Prerequisites for thriving in a dynamic environment: UTSA, College of Business.

Lew, Y.K., Sinkovics, R.R., \& Kuivalainen, O. (2013). Upstream internationalization process: Roles of social capital in creating exploratory capability and market performance. International Business Review, 22(6), 1101-1120.

Linnenluecke, M.K. (2017). Resilience in business and management research: A review of influential publications and a research agenda. International Journal of Management Reviews, 19(1), 4-30. 
Liu, H., Ke, W., Wei, K.K., \& Hua, Z. (2013). The impact of IT capabilities on firm performance: The mediating roles of absorptive capacity and supply chain agility. Decision Support Systems, 54(3), 1452-1462.

Mccann, J., Selsky, J., \& Lee, J. (2009). Building agility, resilience and performance in turbulent environments. People and Strategy, 32(3), 44.

Melnyk, S.A., Closs, D.J., Griffis, S.E., Zobel, C.W., \& Macdonald, J.R. (2014). Understanding supply chain resilience. Supply Chain Management Review, 18(1), 34-41.

Mentzer, J.T., Stank, T., \& Esper, T. (2008). Supply chain management and its relationship to logistics, marketing, production, and operations management. Journal of Business Logistics, 29(1), 31-46.

Mikalef, P., \& Pateli, A. (2017). Information technology-enabled dynamic capabilities and their indirect effect on competitive performance: Findings from pls-sem and fsQCA. Journal of Business Research, 70, 1-16.

Mitręga, M., \& Zolkiewski, J. (2012). Negative consequences of deep relationships with suppliers: An exploratory study in Poland. Industrial Marketing Management, 41(5), 886-894.

Mom, T.J.M., Van Neerijnen, P., Reinmoeller, P., \& Verwaal, E. (2015). Relational capital and individual exploration: Unravelling the influence of goal alignment and knowledge acquisition. Organization Studies, 36(6), 809-829.

Möller, K., \& Svahn, S. (2003). Managing strategic nets a capability perspective. Marketing Theory, 3(2), 209-234.

Nahapiet, J., \& Ghoshal, S. (1998). Social capital, intellectual capital, and the organizational advantage. Academy of Management Review, 23(2), 242-266.

Najafi-Tavani, S., Najafi-Tavani, Z., Naudé, P., Oghazi, P., \& Zeynaloo, E. (2018). How collaborative innovation networks affect new product performance: Product innovation capability, process innovation capability, and absorptive capacity. Industrial Marketing Management.

Najafi-Tavani, S., Sharifi, H., \& Ismail, H.S. (2013). A study of contingency relationships between supplier involvement, absorptive capacity and agile product innovation. International Journal of Operations \& Production Management, 34(1), 65-92.

Pan, Y., \& Jackson, R.T. (2008). Ethnic difference in the relationship between acute inflammation and serum ferritin in us adult males. Epidemiology \& Infection, 136(3), 421-431.

Partanen, J., Möller, K., Westerlund, M., Rajala, R., \& Rajala, A. (2008). Social capital in the growth of science-and-technology-based SMEs. Industrial Marketing Management, 37(5), 513-522.

Pettit, T.J., Croxton, K.L., \& Fiksel, J. (2013). Ensuring supply chain resilience: Development and implementation of an assessment tool. Journal of Business Logistics, 34(1), 46-76.

Pettit, T.J., Fiksel, J., \& Croxton, K.L. (2010). Ensuring supply chain resilience: Development of a conceptual framework. Journal of Business Logistics, 31(1), 1-21.

Piercy, N.F. (2009). Strategic relationships between boundary-spanning functions: Aligning customer relationship management with supplier relationship management. Industrial Marketing Management, 38(8), 857-864.

Pillai, K.G., Hodgkinson, G.P., Kalyanaram, G., \& Nair, S.R. (2017). The negative effects of social capital in organizations: A review and extension. International Journal of Management Reviews, 19(1), $97-124$.

Ping, R.A. (1995). A parsimonious estimating technique for interaction and quadratic latent variables. Journal of Marketing Research, 32(3), 336-347.

Podsakoff, P.M., Mackenzie, S.B., Lee, J.Y., \& Podsakoff, N.P. (2003). Common method biases in behavioral research: A critical review of the literature and recommended remedies. Journal of Applied Psychology, 88(5), 879-903.

Ponomarov, S.Y., \& Holcomb, M.C. (2009). Understanding the concept of supply chain resilience. The International Journal of Logistics Management, 20(1), 124-143.

Powell, T.C. (1992). Organizational alignment as competitive advantage. Strategic Management Journal, 13(2), 119-134.

Preacher, K.J., \& Hayes, A.F. (2008). Asymptotic and resampling strategies for assessing and comparing indirect effects in multiple mediator models. Behavior Research Methods, 40(3), 879-891.

Rogelberg, S.G., \& Stanton, J.M. (2007). Introduction: Understanding and dealing with organizational survey nonresponse. Organizational Research Methods, 10(2), 195-209. 
Rose, D.S., Sidle, S.D., \& Griffith, K.H. (2007). A penny for your thoughts: Monetary incentives improve response rates for company-sponsored employee surveys. Organizational Research Methods, 10(2), 225-240.

Saenz, M.J., Revilla, E., \& Knoppen, D. (2014). Absorptive capacity in buyer-supplier relationships: Empirical evidence of its mediating role. Journal of Supply Chain Management, 50(2), 18-40.

Sheffi, Y., \& Rice, J.B. (2005). A supply chain view of the resilient enterprise. MIT Sloan Management Review, 47(1), 41-48.

Sinkovics, R.R., Jean, R.J.B., Roath, A.S., \& Cavusgil, S.T. (2011). Does IT integration really enhance supplier responsiveness in global supply chains? Management International Review, 1-20.

Stolze, H.J., Murfield, M.L.U., \& Esper, T.L. (2015). The role of social mechanisms in demand and supply integration: An individual network perspective. Journal of Business Logistics, 26(1), 49-68.

Tóth, Z., Henneberg, S.C., \& Naudé, P. (2017). Addressing the 'qualitative' in fuzzy set qualitative comparative analysis: The generic membership evaluation template. Industrial Marketing Management, 63, 192-204.

Trentin, A., Forza, C., \& Perin, E. (2015). Embeddedness and path dependence of organizational capabilities for mass customization and green management: A longitudinal case study in the machinery industry. International Journal of Production Economics, 169, 253-276.

Tsai, W. (2001). Knowledge transfer in intraorganizational networks: Effects of network position and absorptive capacity on business unit innovation and performance. Academy of Management Journal, 44(5), 996-1004.

Tsai, W. (2002). Social structure of "coopetition" within a multiunit organization: Coordination, competition, and intraorganizational knowledge sharing. Organization Science, 13(2), 179-190.

Tsai, W., \& Ghoshal, S. (1998). Social capital and value creation: The role of intrafirm networks. Academy of Management Journal, 41(4), 464-476.

Tukamuhabwa, B.R., Stevenson, M., Busby, J., \& Zorzini, M. (2015). Supply chain resilience: Definition, review and theoretical foundations for further study. International Journal of Production Research, 53(18), 5592-5623.

Van Doorn, S., Heyden, M.L.M., \& Volberda, H.W. (2017). Enhancing entrepreneurial orientation in dynamic environments: The interplay between top management team advice-seeking and absorptive capacity. Long Range Planning, 50(2), 134-144.

Vanpoucke, E., Vereecke, A., \& Muylle, S. (2017). Leveraging the impact of supply chain integration through information technology. International Journal of Operations \& Production Management, 37(4), 510-530.

Williams, P. (2002). The competent boundary spanner. Public administration, 80(1), 103-124.

Williams, Z., Lueg, J.E., Hancock, T., \& Goffnett, S.P. (2018). Positioning through b2b carrier signals: Understanding how service quality is communicated via websites. Industrial Marketing Management.

Wu, F., Yeniyurt, S., Kim, D., \& Cavusgil, S.T. (2006). The impact of information technology on supply chain capabilities and firm performance: A resource-based view. Industrial Marketing Management, 35(4), 493-504.

Xiong, G., \& Bharadwaj, S. (2011). Social capital of young technology firms and their IPO values: The complementary role of relevant absorptive capacity. Journal of Marketing, 75(6), 87-104.

Yaqun, Y., Xiaoming, H., Ndofor, H., \& Zelong, W. (2015). Dynamic capabilities and the speed of strategic change: Evidence from China. Engineering Management, IEEE Transactions on, 62(1), 18-28.

Yli-Renko, H., Autio, E., \& Sapienza, H.J. (2001). Social capital, knowledge acquisition, and knowledge exploitation in young technology-based firms. Strategic Management Journal, 22(6-7), 587-613.

Zahra, S.A. (2010). Harvesting family firms' organizational social capital: A relational perspective. Journal of Management Studies, 47(2), 345-366.

Zahra, S.A., \& George, G. (2002). Absorptive capacity: A review, reconceptualization, and extension. Academy of Management Review, 27(2), 185-203.

Zhang, C., Viswanathan, S., \& Henke, J.W. (2011). The boundary spanning capabilities of purchasing agents in buyer-supplier trust development. Journal of Operations Management, 29(4), 318-328. 


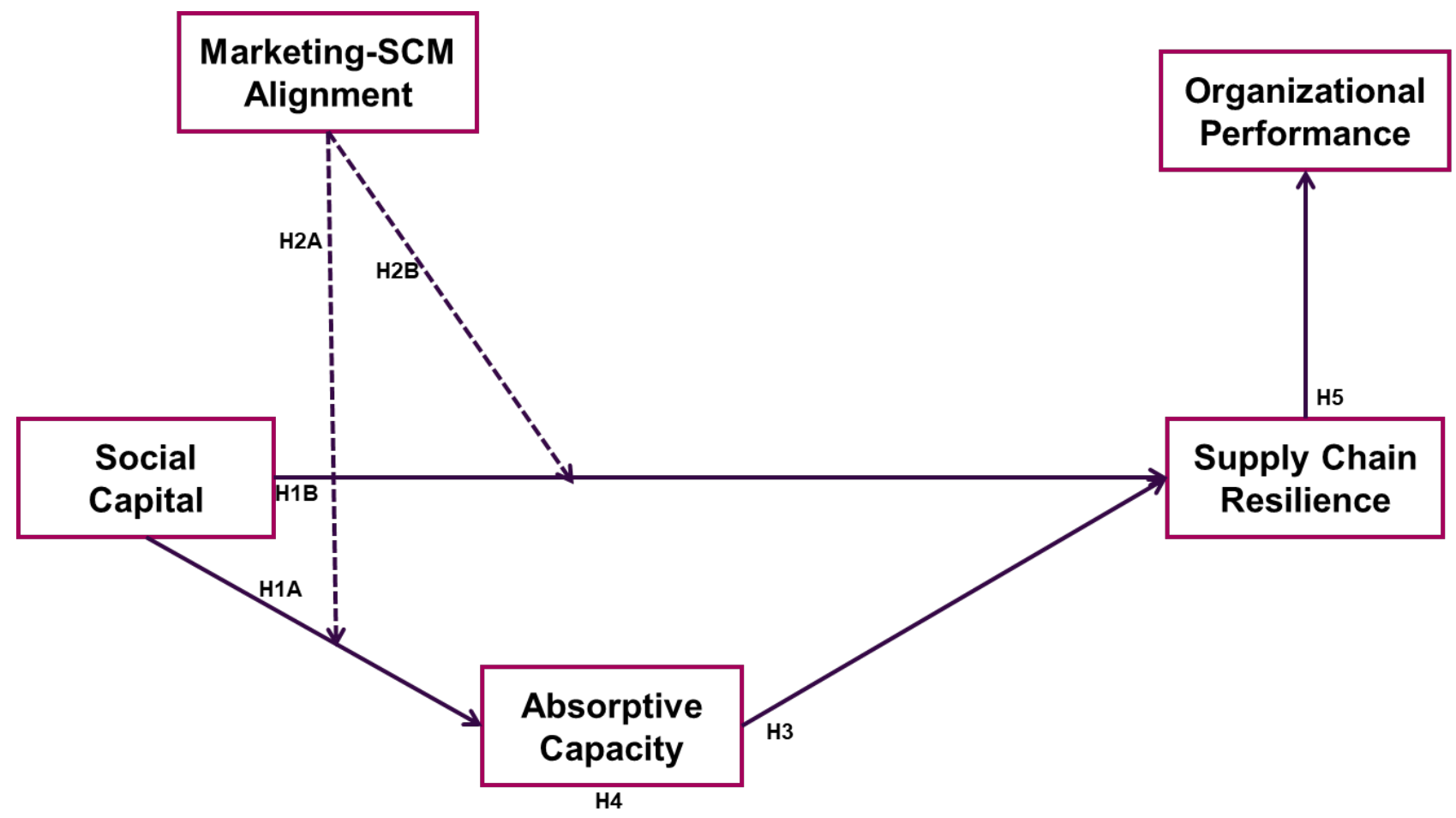

Fig. 1. Conceptual framework 

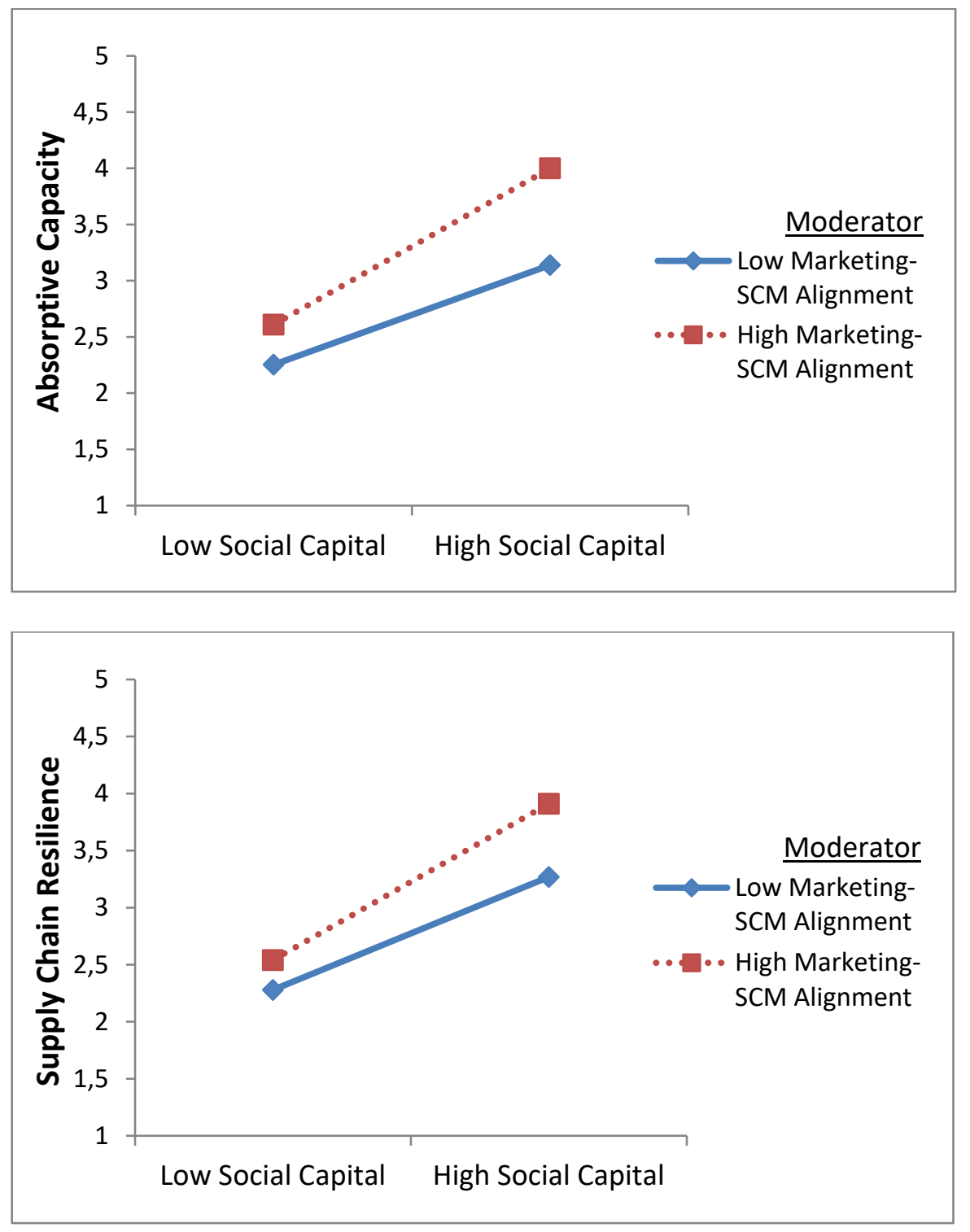

Fig. 2. Moderation effects 
Table 1 Characteristics of sample firms ( $\mathrm{N}=265)$

\begin{tabular}{lcr}
\hline Characteristics & Number & \% \\
\hline Industry sector* & & \\
Chemical and pharmaceutical & 21 & 8 \\
Food and beverage & 30 & 11 \\
Construction equipments & 26 & 10 \\
Retail & 26 & 10 \\
Textile, clothing and apparel & 48 & 18 \\
Metal, iron and steel & 38 & 14 \\
Automotive and related & 19 & 7 \\
Consumer durables, electronics and electrical & 28 & 11 \\
Other industries & 29 & 11 \\
Number of employees & & \\
$\leq 50$ & 43 & 16 \\
$51-250$ & 90 & 34 \\
$>250$ & 132 & 50 \\
Firm age & & \\
$\leq 10$ & 39 & 15 \\
$11-40$ & 159 & 60 \\
$>40$ & 67 & 25 \\
Annual revenue (2013-2014 values) & & \\
-も100 million & 127 & 48 \\
も100 million -499 million & 67 & 25 \\
$>$ Ł500 million & 71 & 27 \\
\hline
\end{tabular}

*Primary industry is identified and selected when participant firm operates in multiple industries. 
Table 2. Measurement items

\section{Constructs}

Standardized loadings $^{\mathrm{a}}$

Social Capital Adapted from Acquah (2007) and Zahra (2010); $\alpha=0.86$

Our firm has a good reputation in its industry

Our firm is well connected to other companies in its industry.

Our firm has a good reputation for fair dealings.

Our firm has access to valuable resources through its business relationships.

Our firm has possibility to acquire and leverage valuable knowledge from its business relationships.

0.78

Absorptive Capacity Adapted from Flatten et al. (2011); $\alpha=0.89$

In our firm, ideas, concepts, and information are communicated smoothly across departments.

In our firm there is a quick information flow, e.g., if a business unit obtains important information it communicates this information promptly to all other business units or departments.

Our employees have the ability to structure and to use collected market knowledge.

Our employees are used to absorb new market knowledge as well as to prepare it for further purposes and to make it available.

Our management supports the implementation of marketing strategies based on acquired market knowledge.

Our firm regularly reconsiders technologies and routines and adapts them accordant to new market knowledge.

Marketing-SCM alignment Adapted from Ashenbaum et al. (2009) and Chen et al. (2007); $\alpha=0.84$

Our performance evaluations are partly based on integrative objectives for supply chain management and marketing.

Employees in supply chain and marketing units are rewarded for working together in our firm.

Employees from marketing and supply chain management are often designated as liaisons to the other function in our firm.

We, employees, all serve to the overarching goals of our firm rather than those of our units.

Our firm extensively utilizes cross-functional work teams between marketing and SCM functions for managing day-to-day operations.

Supply Chain Resilience Adapted from Gölgeci and Ponomarov (2015); $\alpha=0.90$

Our firm's supply chain is able to adequately respond to unexpected disruptions by quickly restoring its product flow.

Our firm's supply chain can quickly return to its original state after being disrupted.

Our firm's supply chain can move to a new, more desirable state after being disrupted.

Our firm's supply chain is well prepared to deal with financial outcomes of potential supply chain disruptions.

Our firm's supply chain has the ability to maintain a desired level of control over structure and function at the time

Organizational performance Adapted from (Collings et al., 2010) and (Demirbag et al., 2014); $\alpha=0.93$

Level of overall costs

Level of overall sales 
Table 3. Descriptive statistics and inter-correlations

\begin{tabular}{llllllllll}
\hline Definition & Mean & S.D. & $\mathbf{1}$ & $\mathbf{2}$ & $\mathbf{3}$ & $\mathbf{4}$ & $\mathbf{5}$ & $\mathbf{6}$ & $\mathbf{7}$ \\
\hline 1 Social capital & 6.39 & 0.61 & & & & & & & \\
2 Absorptive capacity & 5.73 & 0.79 & $0.46^{* *}$ & & & & & \\
3 Marketing-SCM alignment & 5.48 & 0.93 & $0.39^{* *}$ & $0.51^{* *}$ & & & & \\
4 Supply chain resilience & 5.72 & 0.77 & $0.52^{* *}$ & $0.57^{* *}$ & $0.51^{* *}$ & & & \\
5 Organizational performance & 5.42 & 1.06 & $0.38^{* *}$ & $0.40^{* *}$ & $0.30^{* *}$ & $0.31^{* *}$ & & & \\
6 Firm age & 3.63 & 1.08 & $0.21^{* *}$ & -0.04 & -0.10 & -0.03 & 0.04 & & \\
7 Firm size & 3.86 & 2.09 & 0.09 & -0.10 & -0.05 & -0.00 & $0.13^{*}$ & $0.53^{* *}$ \\
\hline
\end{tabular}

Note: $\mathrm{N}=265 .{ }^{*} \mathrm{p}<0.05 ;{ }^{* *} \mathrm{p}<0.01$

Table 4. Convergent and discriminant validity of the measurement model ${ }^{\mathrm{a}}$

\begin{tabular}{lllllllll}
\hline Construct & \#Items & CR & AVE $^{\text {b }}$ & SOC & ACAP & MSA & SCR & OPR \\
\hline Social capital & 5 & 0.88 & 0.60 & 0.77 & & & & \\
Absorptive capacity & 6 & 0.89 & 0.57 & 0.51 & 0.76 & & & \\
Marketing-SCM alignment & 5 & 0.85 & 0.53 & 0.44 & 0.58 & 0.73 & & \\
Supply chain resilience & 6 & 0.90 & 0.63 & 0.58 & 0.62 & 0.59 & 0.79 & \\
Organizational performance & 5 & 0.92 & 0.71 & 0.35 & 0.42 & 0.30 & 0.32 & 0.84 \\
\hline
\end{tabular}

Notes: ${ }^{\mathrm{a}}$ Italicized values on the diagonal are the square root of the AVE values. ${ }^{\mathrm{b}}$ Average variance extracted.

Table 5. Structural model estimation results

\begin{tabular}{ll}
\hline Path & Coefficient (t-value) \\
\hline Direct effects & $0.57(5.23)^{* * *}$ \\
H1A- Social capital $\rightarrow$ Absorptive capacity & $0.59(4.82)^{* * *}$ \\
H1B- Social capital $\rightarrow$ Supply chain resilience & $0.31(3.58)^{* * *}$ \\
H3- Absorptive capacity $\rightarrow$ Supply chain resilience & $0.50(5.44)^{* * *}$ \\
H5- Supply chain resilience $\rightarrow$ Organizational performance & \\
& \\
Moderating effects & $0.13(3.14)^{* *}$ \\
H2A- Marketing-SCM alignment $x$ Social capital $\rightarrow$ Absorptive capacity & $0.10(2.19)^{*}$ \\
H2B- Marketing-SCM alignment X Social capital $\rightarrow$ Supply chain resilience & \\
Control paths & \\
Firm age $\rightarrow$ Absorptive capacity & $-0.02(-0.45)$ \\
Firm size $\rightarrow$ Absorptive capacity & $-0.02(-1.03)$ \\
Firm age $\rightarrow$ Supply chain resilience & $-0.08(-2.12)^{*}$ \\
Firm size $\rightarrow$ Supply chain resilience & $0.03(1.39)$ \\
Firm age $\rightarrow$ Organizational performance & $-0.01(-0.21)$ \\
Firm size $\rightarrow$ Organizational performance & $0.07(1.91)$ \\
\hline Notes: Critical values of the $t$ distribution for $\alpha=0.05, \alpha=0.01$, and $\alpha=0.001($ two-tailed test) & are *=1.96, **=2.58, and \\
$* * *=3.30$, respectively. &
\end{tabular}

